\title{
Change Detection of Rice Cultivation in Bangladesh Based on the Phenological Analysis of MODIS Data
}

\author{
Tarulata Shapla1,2, Jonggeol Park ${ }^{3}$, Chiharu Hongo', Hiroaki Kuze1 \\ ${ }^{1}$ Center for Environmental Remote Sensing, Chiba University, Chiba, Japan \\ ${ }^{2}$ Department of Agroforestry and Environmental Science, Sher-e-Bangla Agricultural University, Dhaka, \\ Bangladesh \\ ${ }^{3}$ Graduate School of Informatics, Tokyo University of Information Sciences, Chiba, Japan \\ Email: tarulatashapla@chiba-u.jp
}

Received 31 October 2015; accepted 14 December 2015; published 17 December 2015

Copyright (C) 2015 by authors and Scientific Research Publishing Inc.

This work is licensed under the Creative Commons Attribution International License (CC BY).

http://creativecommons.org/licenses/by/4.0/

(c) (i) Open Access

\begin{abstract}
Mapping rice cultivation is indispensable for monitoring food supply conditions in Bangladesh because of the economical importance of the crop for supporting ever increasing population in the country. In this paper, we extract the rice paddy field using the MODIS satellite data for five districts of Pabna, Manikganj, Sherpur, Sylhet, and Gazipur, each of which is characterized with its own aspects in terms of rice cultivation. Land classification is implemented using the vegetation index information derived from the red (band 1) and near-infrared (band 2) bands of MODIS 8-day composite time series data for the two time periods of 2001-2003 and 2011-2013. Results of unsupervised classification indicate that the paddy area coverage increased about $4 \%$ and $1 \%$ in Gazipur and Sylhet, respectively. In Pabna, Manikganj, and Sherpur, on the other hand, paddy area decreased by $10 \%, 2 \%$ and $5 \%$, respectively, whereas notable increase of $12 \%, 2 \%$ and $7 \%$ was found in homestead area coverage, which is becoming more and more important for better management of small-scale agroforestry. At the same time, in Sherpur and Sylhet, forest area increased by $1 \%$ and $2 \%$ over the same time period. As a validation of these results, the changes detected in Gazipur are compared with those previously derived from the analysis of Landsat data with higher spatial resolution of $30 \mathrm{~m}$ as compared with that of MODIS $(250 \mathrm{~m})$. Also, the seasonal rice cropping pattern is studied in these five districts for discriminating cultivated rice types. These changes suggest that as a whole, efforts are being made to increase the food production, though the influence of population pressure and economic growth is apparent in these regions.
\end{abstract}

\section{Keywords}

Agroforestry, Rice, Bangladesh, MODIS, Change Detection 


\section{Introduction}

Rice production is of essential importance in Bangladesh, a densely populated country, from the viewpoints of economy as well as food security [1]. Rice solely occupies 76.7\% in the total area under cultivation [2]. There are three major rice types widely cultivated in the country, Aus, Aman and Boro. In the harvest season of 2011-2012, 9.87\%, 48.40\% and 41.73\% of rice production amount consist of Aus, Aman and Boro rice, respectively [3]. Boro, or winter rice, is grown from January to June under irrigated conditions, while the Transplanted Aman (T. Aman or monsoon rice) is grown from July to December, mostly under rain-fed conditions [4]. Currently, Aman rice accounts for about $50 \%$ of the total rice production in the country [5]. The rice yield gap due to biotic and socio-economic constraints in Bangladesh are about 0.9 and 1.3 tons ha ${ }^{-1}$ for the Boro and Aman seasons, respectively. Out of total cultivated areas, single-, double-, and triple-cropping areas were reported to be 2.75, 3.92, and 1.28 million ha, respectively, in the harvesting period of 2005-2006 [6]. More recent data [1] indicate that single-, double-, and triple-cropping areas of Bangladesh are 2.236, 4.107 and 1.485 million ha, respectively.

Due to population pressure, small-scale agriculture has increased considerably in rural areas [7]. The practice of homestead agroforestry with diversified food pattern, in particular, can contribute to reducing the food gaps [8]. Homestead is becoming more and more proliferated throughout Bangladesh for pursuing maximum economic return and proper utilization of land property. In the homesteads of both rural and urban areas, fruit, ornamental and multipurpose trees are produced for improving living environment [9]. The availability of arable land tends to be limited because of the competing influence of industrialization and urbanization. Although forestry contributes to around 5\% of GDP [10], which does not include the value of fuelwood and other minor forest products, deforestation due mainly to the increase in food production can potentially be a cause for environmental degradation [11]. Thus, the monitoring of these land use and land cover (LULC) categories is beneficial for understanding economical as well as environmental situations, in addition to better predicting the yield of rice crops [12].

An extended study of LULC in Bangladesh was reported by Gumma et al. [13], in which Moderate Resolution Imaging Spectroradiometer (MODIS) satellite data taken in year 2010 were used to map rice crop extent and area in Bangladesh. The pixel-level accuracy of the satellite-derived rice area was assessed against the in-situ observation results, and it was found that the rice area estimates were $3 \%$ to $6 \%$ higher than the sub-national statistics for the three major rice species. Also, the yield of Aman rice was estimated using Advanced Very High Resolution Radiometer (AVHRR) data obtained during 1991-2005 in Bangladesh by applying principal components regression [14]. In the present paper, we perform the change detection in LULC in the years of 2001-2003 and 2011-2013. For that purpose, satellite data sets observed with MODIS are analyzed for the following five districts in Bangladesh: Pabna, Manikganj, Sherpur, Sylhet, and Gazipur, with paying attention to the LULC of homestead, paddy, forest and urban areas. All of these districts exemplify typical cases of rice cultivation, as explained in the following section. Unsupervised classification and seasonal analysis of normalized difference vegetation index (NDVI) are exploited for land cover categorization. In addition, the results in Gazipur district are used for validating the accuracy of the present analysis based on MODIS, since the district was analyzed in detail in our previous paper [12], in which the high-resolution data from Landsat were employed for studying LULC in years 2001, 2005 and 2009.

\section{Data Source and Methodology}

\subsection{Study Area}

The research areas are Pabna, Manikganj, Sherpur, Sylhet, and Gazipur in Bangladesh (Figure 1). Pabna is one of the oldest districts of Bangladesh, with population of 2523 thousand (census 2011). It lies in the central western part of the country between $23^{\circ} 48^{\prime}$ and $24^{\circ} 21^{\prime}$ north latitude and between $89^{\circ} 00^{\prime}$ and $89^{\circ} 44^{\prime}$ east longitude, bounded on the east by Manikganj district and the river Jamuna. The total area of the district is $2376.13 \mathrm{~km}^{2}$. Manikganj district (population 1393 thousand) is bounded on the east by Dhaka and on the west by Pabna. The total area of the district is $1383.66 \mathrm{~km}^{2}$, lying between $23^{\circ} 38^{\prime} \mathrm{N}-24^{\circ} 03^{\prime} \mathrm{N}$ and $89^{\circ} 41^{\prime} \mathrm{E}-90^{\circ} 08$ 'E. Sherpur district (population 1358 thousand) lies between $24^{\circ} 18^{\prime} \mathrm{N}-25^{\circ} 18^{\prime} \mathrm{N}$ and $89^{\circ} 53^{\prime} \mathrm{E}-90^{\circ} 91^{\prime} \mathrm{E}$. The total area of the district is $1364.67 \mathrm{~km}^{2}$. Sylhet (population 2675 thousand) is located in the north-eastern part in the country. It is located in a hilly region, with the total area of $3452.07 \mathrm{~km}^{2}$. The district lies between $24^{\circ} 36^{\prime} \mathrm{N}-25^{\circ} 11^{\prime} \mathrm{N}$ and 


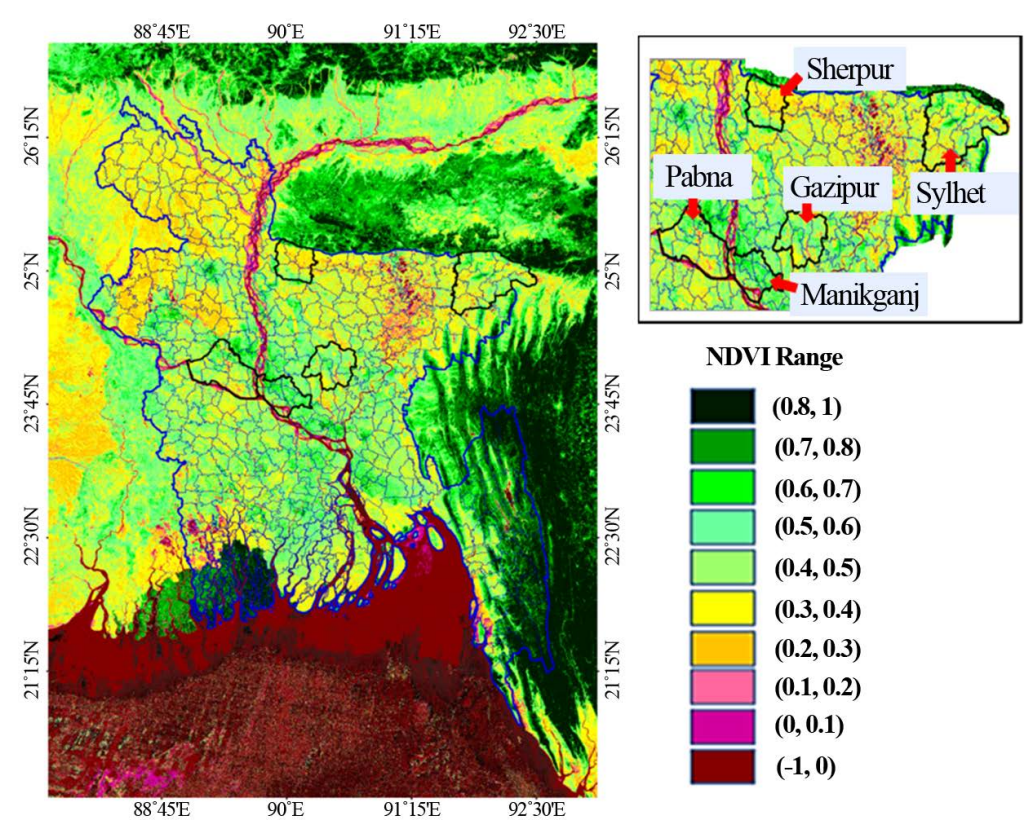

Figure 1. NDVI distribution in Bangladesh derived from MODIS images observed during January 1-8, 2002.

$91^{\circ} 38^{\prime} \mathrm{E}$ and $92^{\circ} 30^{\prime} \mathrm{E}$. Gazipur area (population 3403 thousand in an area of $1741.53 \mathrm{~km}^{2}$ ) is located in the northern neighborhood of Dhaka between latitude $23^{\circ} 88^{\prime} \mathrm{N}-24^{\circ} 34^{\prime} \mathrm{N}$ and longitude $90^{\circ} 15^{\prime} \mathrm{E}-90^{\circ} 70^{\prime} \mathrm{E}$. This district exemplifies a typical rice growing area extending from medium high to highland (between 4 and $24 \mathrm{~m}$ above sea level; ASL) [12]. Among the eight divisions of Bangladesh, Pabna district is enclosed in the Rajshahi division, Gazipur and Manikganj are in a part of Dhaka division, Sherpur is included in the Mymensingh division, and Sylhet district is in the Sylhet division (the same name for the district and division). These five districts in the northern and central areas have been selected for the present study due to intensive rice cultivation therein. These areas, especially Sylhet, are characterized with renewing soil fertility annually through the heavy rainfall with extensive inundations. Pabna district is supposed to have bumper yield from its hybrid (Boro and Aman) paddy fields. Sherpur and Sylhet districts produce all the three types of Aus, Aman and Boro rice [15]. Both Gazipur and Manikganj districts are under the pressure of urbanization because of their proximity to Dhaka, the capital city. Manikganj is characterized with good production in Boro rice [15].

\subsection{Satellite Data and Data Processing}

MODIS/Terra 8-day composites images (MOD09Q1) are used to analyze the LULC of the five districts during the two periods of January 2001-December 2003 and January 2011-December 2013. The images have been selected on the criteria of near-nadir view angle, the absence of clouds or cloud shadows, and relatively low aerosol loading. Band 1 (red, 620 - $670 \mathrm{~nm}$ ) and band 2 (near-infrared, 841 - $876 \mathrm{~nm}$ ) data are processed for characterizing land surface reflectance at 250-m resolution. For each calendar year, forty-six 8-day composite images were downloaded from the Land Processes Distributed Active Archive Center (LPDAAC) (http://pdaac.usgs.gov) of the USGS EROS Data Center (http://edc.usgs.gov/). Two tiles (H25V06, H26V06) were combined together to cover the study area in Bangladesh. As compared with daily collected images, 8-day composite imagery can provide more opportunities to avoid the impact of clouds without substantial changes in the ground conditions, though the actually selected date might be different from pixel to pixel. In order to facilitate the delineation of vegetation coverage, we employ NDVI defined as

$$
N D V I=\frac{N I R-R E D}{N I R+R E D}
$$

where RED and NIR stand for the pixel reflectance for band 1 and 2, respectively. During the analysis, level slicing is applied to the NDVI images produced from each MODIS imagery. For studying changes in LULC, 
138 MODIS images are processed for each of the three year periods of 2001-2003 and 2011-2013. After averaging mostly cloud-free pixels, mosaic images having $4800 \times 4800$ pixels are formed, each pixel representing an area of $250 \times 250 \mathrm{~m}^{2}$. For each of the three-year time periods, we produced 46 images that represent the annual change (46 $\times 8=368$ days) of LULC with reduced influence of clouds. Unsupervised classification (ISODATA algorithm) with 60 isoclusters is implemented for analyzing LULC. Subsequently, fast Fourier transform (FFT) analysis is applied to the NDVI time series for analyzing the seasonal, phenological variation. All the pixels in the five districts are subjected to the FFT analysis in the 46 MODIS-derived NDVI images. In addition to the ISODATA analysis, the FFT result is useful for discriminating different surface coverage types of homestead, forest and rice paddy, including the phenological information related to single-, double-, and triple rice cropping. Additionally, in Gazipur district, three Landsat images observed in 2001, 2005, and 2009 are employed to study changes in LULC [12]. The information of Landsat band 1 through band 4, as well as that of band 5 (1.65 $\mu \mathrm{m})$ and band $7(2.22 \mu \mathrm{m})$ of Landsat TM and ETM+ was exploited in our previous work [12]. Because of the higher resolution of Landsat $(30 \mathrm{~m})$, the resulting classification images are useful for implementing the validation of the MODIS NDVI /FFT analysis.

\section{Results and Discussion}

\subsection{Spatial Distribution of NDVI}

The spatial distribution of NDVI in Bangladesh in January 2002 is shown in Figure 1. Since this result is based on the analysis of MODIS data in January, it is likely that the relatively high NDVI values in the low lying areas represent the harvesting season of Boro rice. Except the hilly area along the eastern coast of the Bay of Bengal (Chittagong division), the major part of the country is on the Ganges-Brahmaputra Delta, where the value of NDVI ranges from $\sim 0.2$ to $\sim 0.7$. In the northern highland districts including Sherpur and Sylhet, NDVI values are relatively low $(\sim 0.2$ to $\sim 0.4)$, whereas in the midland including Pabna, Manikganj and Gazipur, the values are relatively high ( $\sim .3$ to $\sim 0.7$ ). In general, large NDVI values are seen in October (due mainly to Aman rice), while the value tends to be small in February due to low rainfall in the winter season.

\subsection{LULC Classification and Change Detection}

Figure 2 shows the results of LULC analysis for the five districts of Pabna, Manikganj, Sherpur, Sylhet, and Gazipur for the two periods of 2001-2003 and 2011-2013. A noticeable change seen in Pabna is that significant part of the paddy field coverage during 2001-2003 was turned into homestead in the map during 2011-2013, especially in Santhia and Sujanagar, in addition to some other sub-districts. The opposite change from homestead to paddy is seen in the northern rim of Chatmohar, Bhangura and Faridpur sub-districts. Similarly, remarkable changes from homestead to paddy are found in Manikganj, particularly in the western part of Shivalaya subdistrict and southern part of Harirampur sub-district. In Sherpur, the land coverage changed from paddy to homestead in the northern sub-districts of Sreebardi, Jhenaigati and Nalitabari. In association with the increase in paddy area, a slight decrease in forest occurred in the northern area. Sylhet division experienced a considerable change from homestead to paddy in Kanaighat, Jaintiapur, Gowainghat and Companiganj sub-districts. The opposite change from paddy to homestead is found in the southern part of Golabganj and Balaganj sub-districts. In the central part of Sylhet, forest area decreased due to the increase in the paddy land cover. In Gazipur, increase in paddy coverage occurred in both the northern (Sreepur) and southern (Gazipur Sadar and Kaliganj) sub-districts. In the south western part of Gazipur Sadar, the development of urban area is conspicuous [12].

Figure 3 shows pie charts for the category percentage of Pabna, Manikganj, Sherpur, Sylhet, and Gazipur districts in the two different time periods. It is obvious that the paddy category is significant in Pabna, Manikganj, and Sherpur, while homestead is significant in Sylhet and Gazipur. In Pabna and Sherpur, homestead increased from $25 \%$ to $37 \%$ and from $9 \%$ to $16 \%$, respectively. No forest areas were found in Pabna and Manikganj. The decrease in forest area in Gazipur from $11 \%$ to $5 \%$ is alarming from the viewpoint of eco-diversity [12]. The urban category was found only in Gazipur, in which the urbanization occurred in association with deforestation.

The reason behind these changes is presumably the ever increasing population density. During the ten year period from 2001 to 2011, the increase in population density was in Pabna: 916 to $1062 \mathrm{~km}^{-2}$, Manikganj: 928 to $1007 \mathrm{~km}^{-2}$, Sherpur: 937 to $995 \mathrm{~km}^{-2}$, Sylhet: 520 to $775 \mathrm{~km}^{-2}$, and Gazipur: 1165 to $1954 \mathrm{~km}^{-2}$. In Gazipur, population increase and urbanization are the leading causes for the observed change in LULC. In addition to 

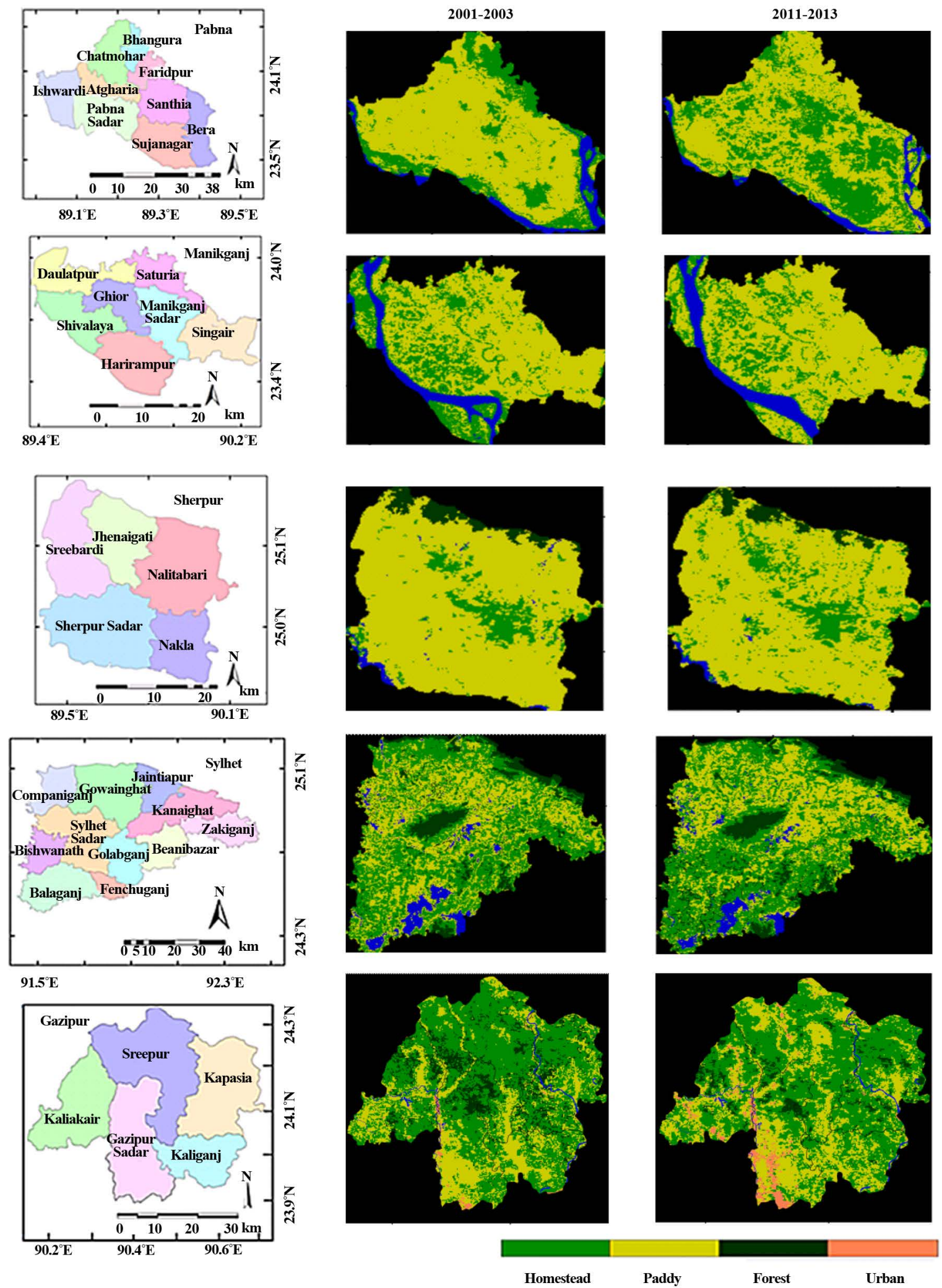

Figure 2. Change detection based on the land-cover classification in Pabna, Manikganj, Sherpur, Sylhet, and Gazipur generated from MODIS (MOD09Q1) data. 


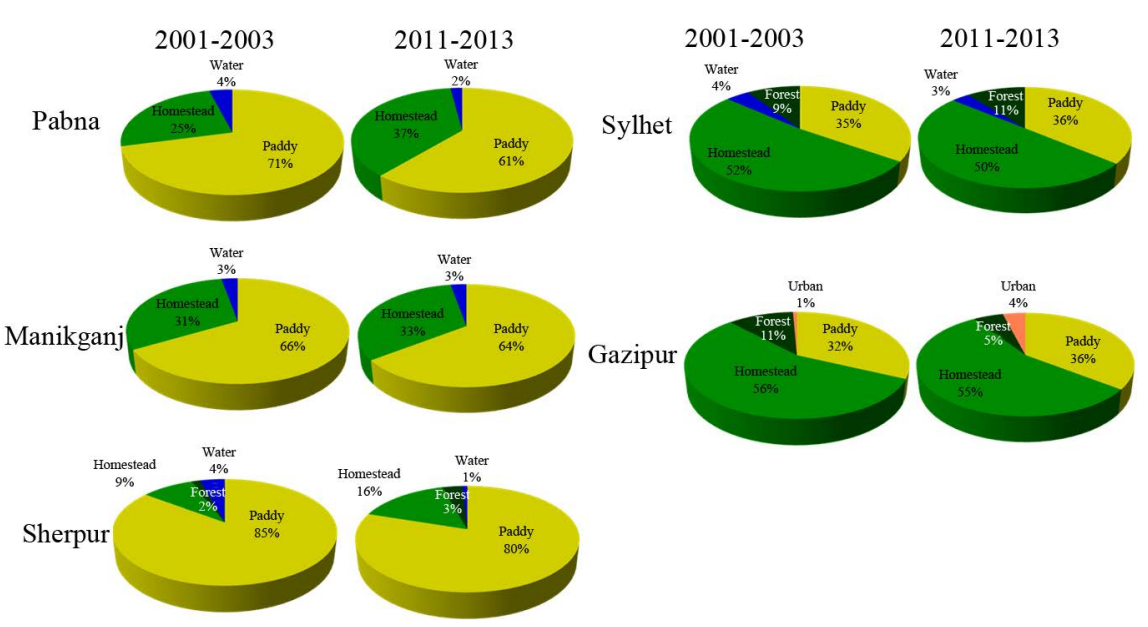

Figure 3. Category percentage in Pabna, Manikganj, Sherpur, Sylhet, and Gazipur districts in two different time periods of 2001-2003 and 2011-2013.

population increase, changes in weather patterns exerted dramatic impacts on agricultural conditions. For example, during 2008-2009, flooding and excessive rain damaged the production of Aman rice (27.6\% partial damage) in Pabna [1]. Similarly in Manikganj and Sherpur, longer flooding and higher flood water level caused soil erosion nearby the Padma River, leading to more and more changes in crop and homestead areas. Due to flood and rush of water in Sylhet, 46.71\% of Boro rice was damaged in 2009-2010 (April-May). In 2003-2012, annual rainfall increased by $809 \mathrm{~mm}$ in Sylhet, while in Dhaka, the value decreased by $364 \mathrm{~mm}$ [1]. Such disastrous flooding and drought events occur as a result of changing rainfall patterns, presumably under the influence of global climate change.

\subsection{Annual Change of NDVI}

In this section, we discuss the results of seasonal change of NDVI as well as those from the FFT analysis applied to the five districts of Gazipur, Pabna, Manikganj, Sherpur, and Sylhet. Figure 4 shows the LULC change in Gazipur detected using the MODIS data during a ten-year period of 2001-2011. From Figure 4(a) and Figure 4(b), it is evident that in the Kaliganj sub-district in the southeastern part of Gazipur, the cropping pattern changed considerably from single to triple cropping pattern. Figure 4(c) shows the annual change of NDVI for the Kaliganj sub-district, as indicated by squares in Figure 4(a) and Figure 4(b). Figure 4(d) shows the frequency amplitude in Kaliganj, where the peak at f1 during 2001-2003 indicates the dominance of the single cropping pattern. In both Figure 4(c) and Figure 4(d), the change of NDVI variation patterns clearly indicates that the single cropping pattern during 2001-2003 had been replaced with the double to triple cropping pattern during the more recent period of 2011-2013.

Figure 5 shows the annual variation of NDVI and its frequency amplitude during the period of 2011-2013 for the four districts of Pabna, Manikganj, Sherpur, and Sylhet. In Pabna (Figure 5(a)), it is found that the triple cropping pattern is dominating, followed by double- and single-cropping areas. In Pabna Sadar (southwestern sub-district), both double- and triple-cropping systems are located. In Bera (eastern sub-district), the peak corresponding to single-cropping is observed in the middle of August, representing the growing stage of Aman rice. In Manikganj (Figure 5(b)), all the three cropping patterns are found. In Garpara, which is a union under the Manikganj Sadar sub-district, the single cropping peak is seen in the middle of August, corresponding to the growth of Aman rice. In Saturia and Tilli, which are unions included in the Saturia sub-district, double peaks appear around March and October.

In Sherpur (Figure 5(c)), the single cropping pattern is found in the northwestern sub-district of Sreebardi (a peak in August corresponding to Aman), the double cropping in Sreebardi and Nakla (southeast, from midFebruary to early April), and the triple pattern in Nalitabari (northeast, mid-May to early July). In Sylhet (Figure 5(d)), the single pattern is seen in the northern region of Gowainghat (from early October to December), the double cropping pattern in Horipur (a union under Jaintiapur sub-district) (late August to early October), and the triple pattern in Horipur (early October to mid-November). 
(a) Gazipur 2001

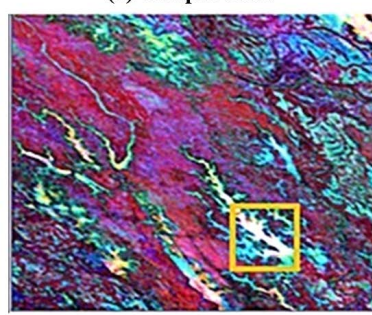

(c) NDVI (Kaliganj)

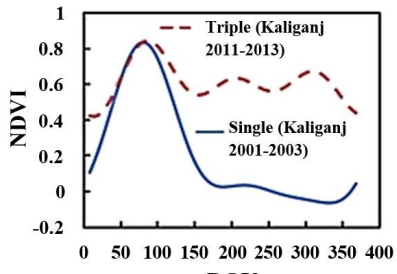

DOY (b) Gazipur 2011

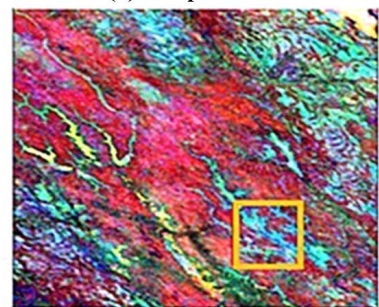

(d) Frequency amplitude (a.u.) Kaliganj

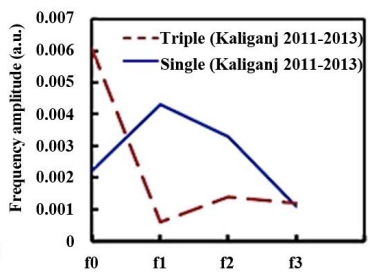

Figure 4. Change detection from MODIS generated data in Gazipur. Different colors indicate: white (paddy, single cropping), yellow (paddy, double), light blue (paddy, triple), maroon (homestead), black (urban), and dark maroon (forest), in (a) 2001 and (b) 2011. (c) annual change in NDVI and (d) the corresponding frequency amplitude in Kaliganj sub-district of Gazipur.

(a) Pabna

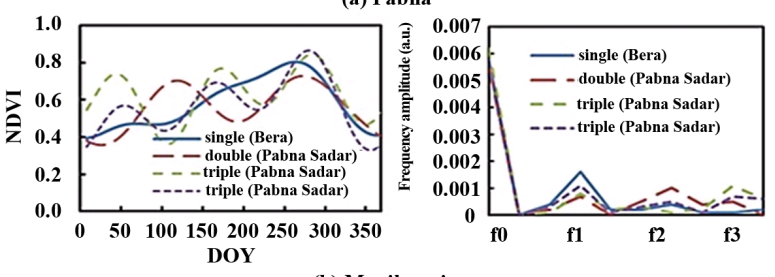

(b) Manikganj
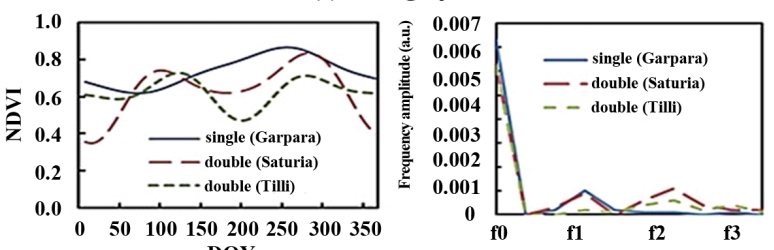

DOY

(c) Sherpur
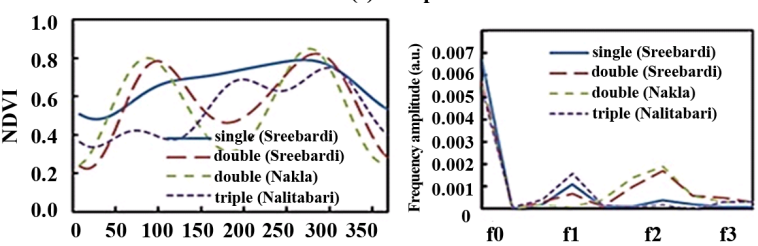

DOY

(d) Sylhet
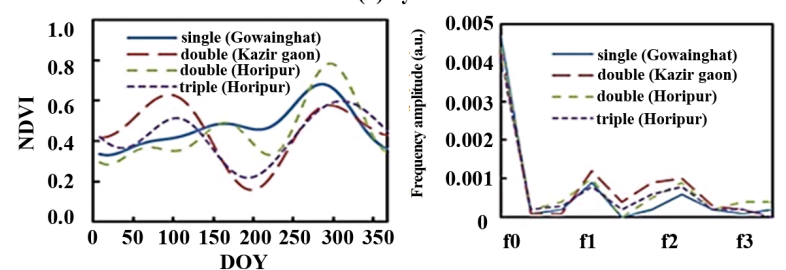

Figure 5. Annual variation of NDVI and its frequency amplitude during the period of 2011-2013 for the four districts of (a) Pabna, (b) Manikganj, (c) Sherpur, and (d) Sylhet. 


\subsection{Interpretation of LULC Change in Relation to Rice Cultivation}

Figure 6 delineates the three types of rice cropping pattern (single, double and triple) in the five districts. Among the pixels showing phenological changes detected with the FFT analysis, the highest fraction is attributed to double cropping. Especially in Pabna, a significant proportion (73\%) is categorized as double cropping, whereas in other three districts, the fractions are slightly less than 50\%. The double cropping areas in Pabna are distributed in the northern part (Bhangura and Faridpur) and eastern part (Bera), which is within the flood plain of the Ganges River. For triple cropping, the highest fraction of $27 \%$ is observed in Sherpur, mostly in the southwestern sub-district of Sherpur Sadar. In Gazipur and Manikganj, 46\% and 40\% of rice cropping area is categorized into single cropping pattern, respectively. Although single cropping areas are rather scattered in Gazipur, it is concentrated in the northeastern part (Singair and Saturia) in Manikganj.

According to the BBS report in 2011-2012 [1], single, double and triple cropping fractions in Pabna are 21\%, $56 \%$ and 23\%, respectively, whereas in Sylhet, the fractions are 59\%, 32\% and 9\% and in Dhaka (neighboring Gazipur and Manikganj), the numbers are $46 \%, 40 \%$ and $14 \%$, respectively. These fractions are similar to the present result (Figure 6), though double cropping (48\%) surpasses single cropping (37\%) in Sylhet according to the present FFT analysis.

\subsection{Accuracy Assessment of MODIS Classification}

In the four districts of Pabna, Manikganj, Sherpur, and Sylhet, we have examined the accuracy of the MODIS classification results against the Google Earth image, originally obtained as Digital Globe imagery observed in 2007 and 2010. In Pabna, for example, correctly classified pixels in 2001-2003 are 401 (homestead) and 4179 (paddy), whereas 96 pixels in homestead (76 pixel in paddy) are misclassified as paddy (homestead), resulting in the kappa value of 0.864. In 2011-2013, however, most of the pixels that belong to homestead (496) and paddy (4255) are classified correctly, leading to the kappa value of 0.999 . In a similar way, the resulting kappa values are between 0.729 (Manikganj 2011-2013) and 1.00 (Manikganj 2001-2003 and Sherpur 2011-2013) in the present classification results.

Furthermore, for Gazipur, we compare the accuracy of classification results obtained from the MODIS (year 2011) and Landsat (year 2009) data. The pixel numbers are 8855 for MODIS and 4535 for Landsat, and they

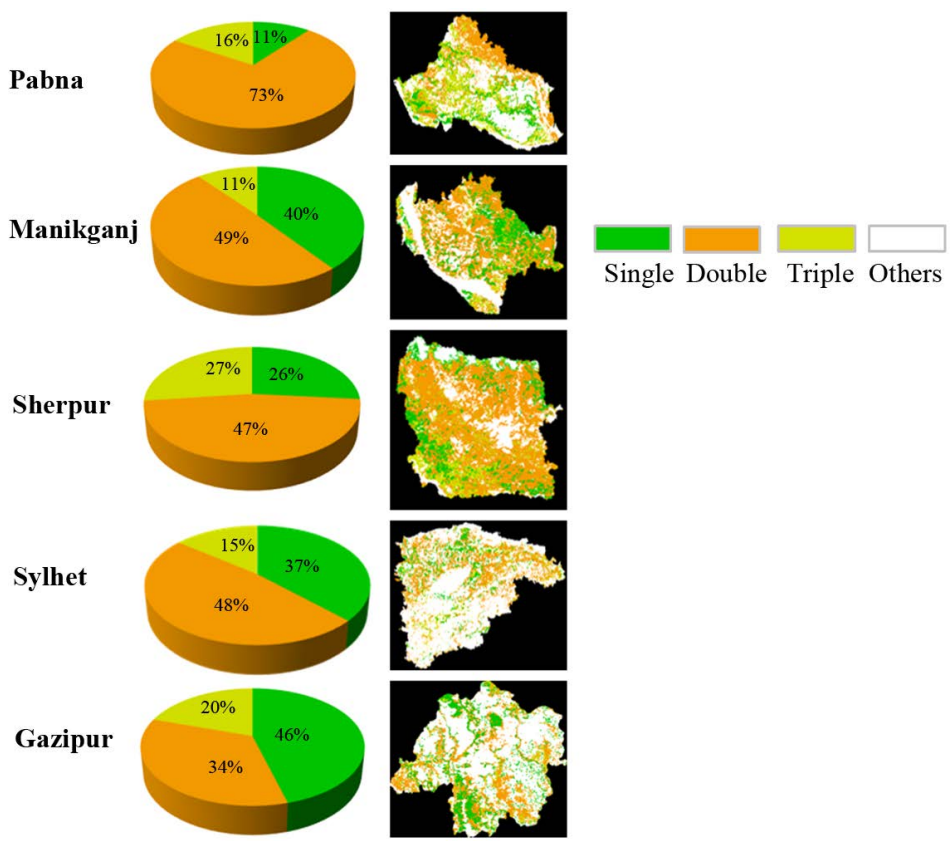

Figure 6. Single, double and triple rice cropping pattern on a percentile basis for Pabna, Manikganj, Sherpur, Sylhet and Gazipur generated from MODIS data (2011-2013). 
are compared with the Google Earth imagery separately. The MODIS result in 2011 indicates that in Gazipur, homestead, paddy, forest, and urban areas are found to be $55 \%, 36 \%, 5 \%$, and $4 \%$, respectively. In Landsat result in 2009 , on the other hand, the fractions are $57 \%, 37 \%, 3 \%$, and $3 \%$, respectively [12]. Thus, these results are fairly consistent with each other, in spite of the temporal difference of two years. For further checking the influence of the difference in the spatial resolution, we re-sampled the MODIS image with the resolution of Landsat, and constructed an accuracy table (Table 1). As expected, higher resolution (30 m) of Landsat results in better classification result (kappa $=0.82$ ) than the counterpart from the MODIS analysis (kappa $=0.65$ ). In other words, because of its coarse resolution of $250 \mathrm{~m}$, a single MODIS pixel tends to contain many objects [16] [17]. Figure 7 shows the examples of double rice cropping and homestead areas observed in Joydebpur in the Gazipur Sadar sub-district. The rice production conditions in these areas were confirmed by our extensive field survey carried out from September 2013 to January 2014 using the global positioning system (GPS), in addition to the Google Earth imagery.
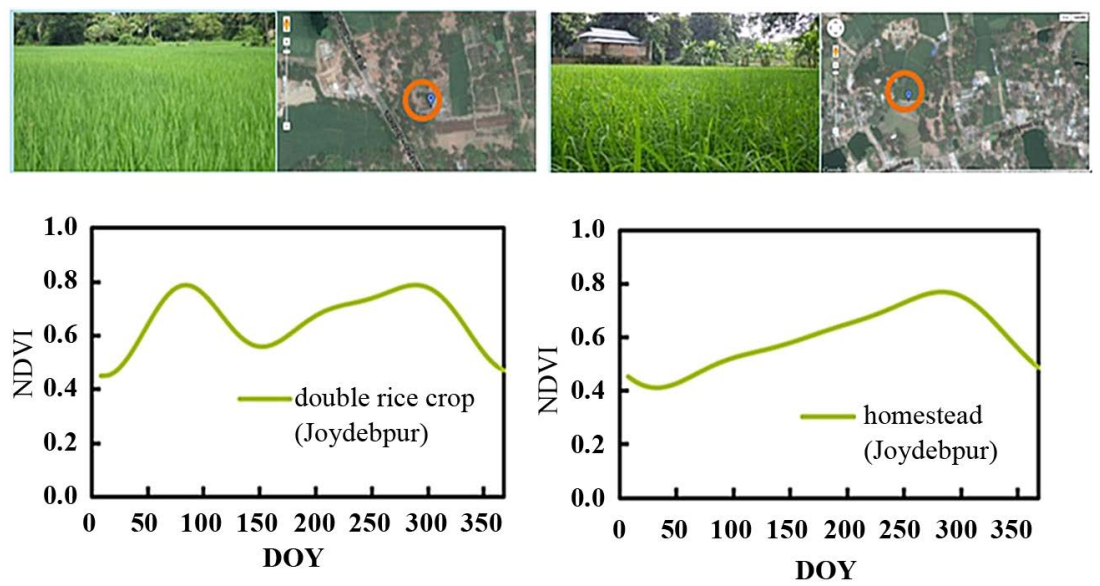

Figure 7. Examples of double cropping and homestead areas detected in Joydebpur under the sub-district of Gazipur Sadar, where our extensive field survey was conducted from September 2013 to January 2014.

Table 1. Accuracy table of re-sampled MODIS image with the resolution of Landsat.

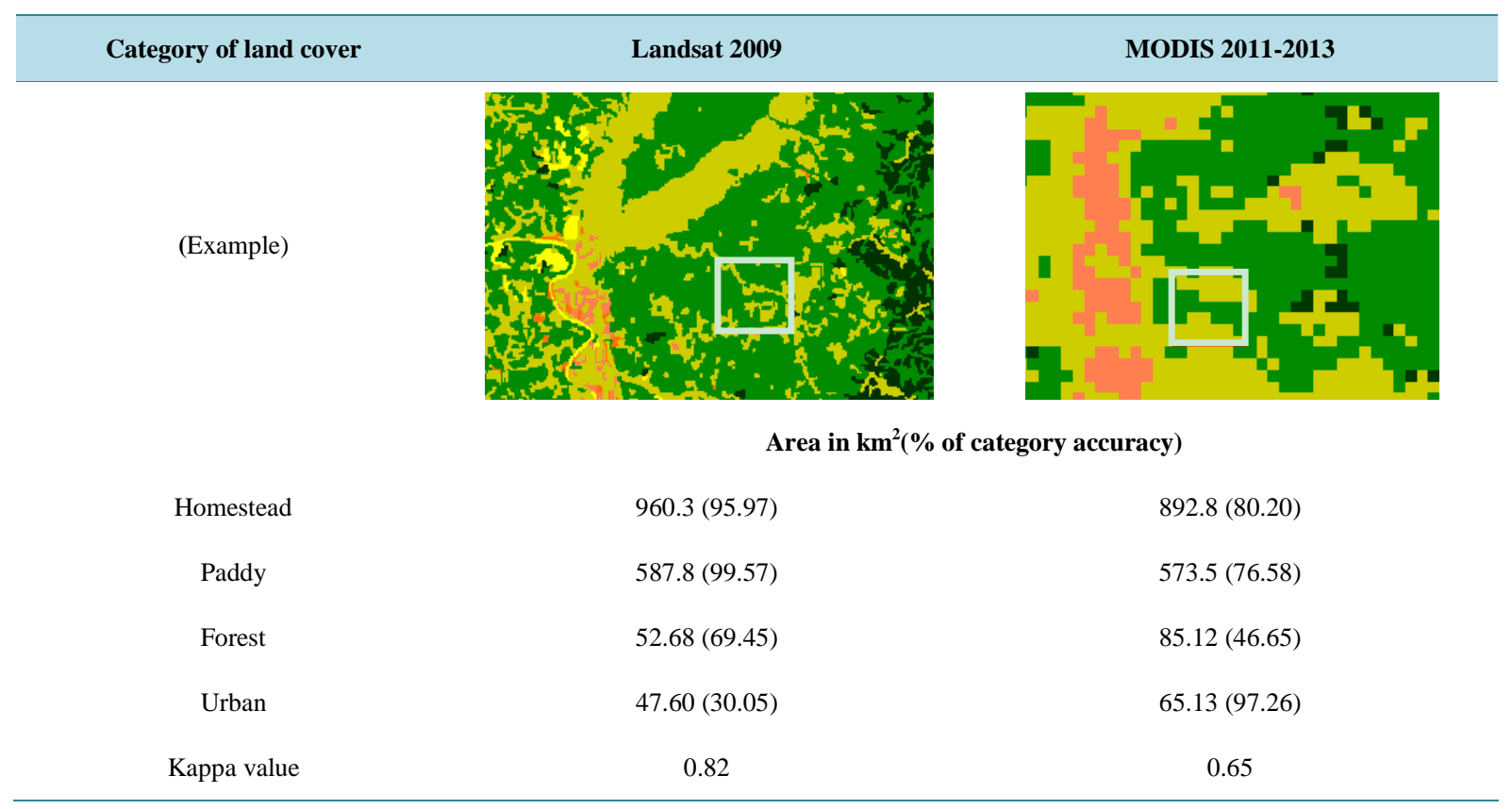




\section{Conclusions}

MODIS images were used to detect changes of paddy cultivation in Bangladesh on the basis of the phenological study of the five districts of Pabna, Manikganj, Sherpur, Sylhet, and Gazipur during two time periods of 20012003 and 2011-2013. In these five districts, the major changes detected during the ten year period can be summarized as follows. In the northwestern district of Pabna, paddy coverage dropped by about $10 \%$ (71\% to 61\%), due mainly to the conversion to homestead. Similar decline of paddy was found also in Sherpur (85\% to $80 \%)$ in mid-western part of the country. In Manikganj, on the other hand, the relative fractions of paddy (66\%) and homestead (31\%) remained nearly the same even after ten years (64\% and 33\%). Similarly in Sylhet, the mideastern part, homestead (52\%) and paddy (35\%) coverage was more or less unchanged (50\% and 36\%). Similar dominance of homestead (56\%) followed by paddy (32\%) remained nearly unchanged (55\% and 36\%) also in Gazipur, a midland district next to the capital Dhaka, though the slight increase in paddy occurred at the expense of the decline found mainly in the forest coverage (11\% to 5\%). The predominance of homestead coverage in both Sylhet and Gazipur is ascribable to the influence of increasing population as well as economic pressure in these two districts, as compared with other three districts (Pabna, Manikganj, and Sherpur) where population increase is comparatively moderate.

In terms of the rice cropping pattern, the frequency analysis of NDVI indicated that the single cropping is dominant only in Gazipur (46\%). The dominance of double cropping pattern is significant in Pabna (73\%). The highest fraction of triple cropping was seen for Sherpur (27\%), followed by Gazipur (20\%). Generally, the introduction of triple cropping can contribute to increasing the total production, though water is the limiting factor with climatic and other factors. This research can be used as a foundation for continuous mapping of rice and related land coverage using satellite images that will be useful for monitoring the land use conditions on regional as well as national scales. In future, more long-term studies covering wider areas will provide valuable knowledge on the influence of climate change on the agricultural conditions and food security in the country.

\section{Acknowledgements}

One of the authors (T.S) gratefully acknowledges the financial support of Watanuki Foundation, Chiba, Japan, during the course of this study.

\section{References}

[1] Bangladesh Bureau of Statistics (2010-2012) Statistical Yearbook of Bangladesh. Govt. of Bangladesh, Dhaka.

[2] Sattar, S.A. (2000) Bridging the Rice Yield Gap in Bangladesh. In: Papademetriou, M.K., Dent, F.J. and Herath, E.M., Eds., Bridging the Rice Yield Gap in the Asia-Pacific Region, FAO Regional Office of the UN for Asia and the Pacific, Bangkok.

[3] http://www.riice.org//mapping-forecasting

[4] Wang, L.-F., Kong, J.A., Ding, K.H., Le Toan, T., Ribbes, F. and Floury, N. (2005) Electromagetic Scattering Model for Rice Canopy Based on Monte Carlo Simulation. Progress in Electromagnetic Research, 52, 153-171. http://dx.doi.org/10.2528/PIER04080601

[5] Rashid, M.M. (1994) Rice Production in Bangladesh: Programmes, Achievements, Potentials and Challenges. International Rice Commission Newsletter, 43, 9-18.

[6] Bangladesh Rice Research Institute (2006) Improvement of Standard Boro Rice. BRRI Annual Report for July 2005June 2006.

[7] Haque, M.A. (1994) Village and Farm Forestry in Bangladesh. Joint. Pub. Bangladesh Agric. Univ., Mymensingh, and Swiss Dev. Coop., Dhaka.

[8] Azim, M.A., Rashid, M.M., Rahman, M.M., Alam, M.M. and Begum, J. (2007) A Study on Nutritional and SocioEconomic Level of the Rural Household in Gazipur District. Pakistan Journal of Nutrition, 6, 138-142. http://dx.doi.org/10.3923/pjn.2007.138.142

[9] Hocking, D. and Haque, M.A. (1989) Village and Farm Forestry in Bangladesh. Brief Evaluation Report. Swiss Dev. Coop., Dhaka.

[10] Bangladesh Forest Department (2005) Participatory Forestry, A Quarterly Newsletter of Forest Department's Ongoing Forestry Sector Project, Bulletin No. 4, September.

[11] Communities and Forest Management in South Asia. https://books.google.co.jp/books?isbn=2831705541 
[12] Shapla, T., Park, J.-G., Hongo, C. and Kuze, H. (2015) Agricultural Land Cover Change in Gazipur, Bangladesh, in Relation to Local Economy Studied Using Landsat Images. Advances in Remote Sensing, 4, 214-223. http://dx.doi.org/10.4236/ars.2015.43017

[13] Gumma, M.K., Thenkabail, P.S., Maunahan, A., Islam, S. and Nelson, A. (2014) Mapping Seasonal Rice Cropland Extent and Area in the High Cropping Intensity Environment of Bangladesh Using MODIS 500 m Data for the Year 2010. ISPRS Journal of Photogrammetry and Remote Sensing, 91, 98-113. http://dx.doi.org/10.1016/j.isprsjprs.2014.02.007

[14] Rahman, A., Kaisar, K., Krakauer, N.Y., Roytman, L. and Kogan, F. (2012) Use of Remote Sensing Data for Estimation of Aman Rice Yield. International Journal of Agriculture and Forestry, 2, 101-107. http://dx.doi.org/10.5923/j.ijaf.20120201.16

[15] https://publications.csiro.au/rpr/download?pid=csiro:EP141373\&dsid=DS6

[16] Strahler, A., Woodcock, C. and Smith, J. (1986) On the Nature of Models in Remote Sensing. Remote Sensing of Environment, 20, 121-139. http://dx.doi.org/10.1016/0034-4257(86)90018-0

[17] Wulder, M.A., Hall, R.J., Coops, N.C. and Franklin, S.E. (2004) High Spatial Resolution Remotely Sensed Data for Ecosystem Characterization. BioScience, 54, 511-521. http://dx.doi.org/10.1641/0006-3568(2004)054[0511:hsrrsd]2.0.co;2 